\title{
Motivational interviewing for improving oral health, a commentary on two reviews
}

\begin{tabular}{|c|c|c|}
\hline $\begin{array}{l}\text { Abstracted } \\
\text { from }\end{array}$ & $\begin{array}{l}\text { Gao X, Lo EC, Kot SC, Chan KC } \\
\text { Motivational interviewing in improving oral } \\
\text { health: a systematic review of randomized } \\
\text { controlled trials. J Periodontol 2014; 85: } 426 \text { - } \\
\text { 437. doi: 10.1902/jop.2013.130205. Epub } 2013 \\
\text { Jun 27. PubMed PMID: } 23805818 \text {. }\end{array}$ & $\begin{array}{l}\text { Cascaes AM, Bielemann RM Clark VL, Barros AJ. } \\
\text { Effectiveness of motivational interviewing at improving } \\
\text { oral health: a systematic review } \\
\text { Rev Saude Publica 2014; 48: 142-153. } \\
\text { PubMed PMID 24789647. }\end{array}$ \\
\hline $\begin{array}{l}\text { Address for } \\
\text { correspondence: }\end{array}$ & $\begin{array}{l}\text { Dr. Xiaoli Gao, Research Assistant Professor, Dental } \\
\text { Public Health, Faculty of Dentistry, The University of } \\
\text { Hong Kong, 3/F, Prince Philip Dental Hospital, } 34 \\
\text { Hospital Road, Sai Ying Pun, Hong Kong } \\
\text { E-mail: gaoxl@hkucc.hku.hk }\end{array}$ & $\begin{array}{l}\text { Andreia Morales Cascaes, Faculdade de Odontologia } \\
\text { Departamento de Odontologia Social e Preventiva Universidade } \\
\text { Federal de Pelotas Rua Gonçalves Chaves, } 457 \text { 96015-560 Pelotas, } \\
\text { RS, Brasil } \\
\text { E-mail: andreiacascaes@hotmail.com }\end{array}$ \\
\hline Question: & \multicolumn{2}{|c|}{ Is motivational interviewing more effective than conventional education in changing oral health behaviours? } \\
\hline Data sources & $\begin{array}{l}\text { PubMed-Medline, Web of Science, Cochrane Library } \\
\text { and PsycINFO }\end{array}$ & $\begin{array}{l}\text { PubMed, LILACS, SciELO, PsycINFO, Cochrane Database of } \\
\text { Systematic Reviews and Google Scholar. }\end{array}$ \\
\hline Study selection & $\begin{array}{l}\text { Randomised controlled trials involving motivational } \\
\text { interviewing (MI) as an active element of interventions } \\
\text { and comparing with normative advice (CE) were } \\
\text { included. }\end{array}$ & $\begin{array}{l}\text { Controlled studies that aimed to teach the MI approach to } \\
\text { professionals or students and included one or more intervention } \\
\text { groups other than Ml or traditional education. }\end{array}$ \\
\hline $\begin{array}{l}\text { Data extraction and } \\
\text { synthesis }\end{array}$ & $\begin{array}{l}\text { Screening, selection and quality assessment were carried } \\
\text { out independently by two reviewers. } \\
\text { Qualitative synthesis was conducted owing to } \\
\text { heterogeneity of included studies. }\end{array}$ & $\begin{array}{l}\text { Two reviewers carried out study selection and quality assessment } \\
\text { independently. A scoring instrument was used for the quality } \\
\text { assessment. }\end{array}$ \\
\hline Results & $\begin{array}{l}\text { Sixteen studies were included. Seven studies considered } \\
\text { periodontal health, with MI outperforming CE with } \\
\text { bigger improvement in at least one outcome in five } \\
\text { studies. MI alsooutperformed CE in at least one outcome } \\
\text { in four studies on preventing early childhood caries. } \\
\text { In addition, better performance by MI was seen in } \\
\text { one study on adherence to dental appointment and } \\
\text { twofourstudies on abstinence of illicit drugs and alcohol } \\
\text { use to prevent the re-occurrence of facial injury. }\end{array}$ & $\begin{array}{l}\text { Ten RCTs were included. Six were conducted in adults and four } \\
\text { with parents of young children. The Ml interventions varied in } \\
\text { duration ( } 15 \text { to } 90 \text { minutes) and number of sessions (one to } \\
\text { seven). } \\
\text { Five studies used a trained counsellor with extensive } \mathrm{Ml} \\
\text { experience. Five interventions assessed the impact of } \mathrm{Ml} \text { on } \\
\text { oral health behaviours and nine on clinical outcomes (three on } \\
\text { dental caries, six on dental plaque, four on gingivitis and three on } \\
\text { periodontal pockets). Four studies reported positive effects of Ml } \\
\text { on oral health outcomes whereas another four showed null effect. }\end{array}$ \\
\hline Conclusions & $\begin{array}{l}\text { Reviewed randomised controlledtrials showed varied } \\
\text { success of } \mathrm{Ml} \text { in improving oral health. The potential } \\
\text { of } \mathrm{Ml} \text { in dental healthcare, especially on improving } \\
\text { periodontal health, remains controversial. } \\
\text { Further studies with methodological rigour are needed } \\
\text { for a better understanding of the roles of } \mathrm{Ml} \text { in dental } \\
\text { practice. }\end{array}$ & $\begin{array}{l}\text { We found inconclusive effectiveness for most oral health } \\
\text { outcomes. We needmore and better-designed and reported } \\
\text { interventions to fully assess the impact of Ml on oral health } \\
\text { and understand the appropriate dosage for the counseling } \\
\text { interventions. }\end{array}$ \\
\hline
\end{tabular}




\section{Commentary}

It is now widely understood that changing behaviour should be a priority for healthcare professionals in order to prevent morbidity and mortality (NICE, 2014). ${ }^{1}$ In the area of oral health, lifestyle risk behaviours such as high sugar consumption, poor oral hygiene, lack of use of fluoride toothpaste, smoking and tobacco use and excess alcohol consumption contribute to poor oral health outcomes.

Practitioners and researchers are interested in developing effective interventions that can be delivered in a dental setting, that will reduce harmful behaviours and increase self-care of oral health hygiene. Healthcare Improvement Scotland $(2014)^{2}$ recommends delivery of brief behaviour change interventions in the dental setting. However, these interventions require development in their design and reporting in order to create a sound evidence base (Healthcare Improvement Scotland, 2014).

The application of brief interventions to dentistry is a new field of research. There has been particular interest in the use of 'motivational interviewing' due to its success in changing behaviour in areas such as addiction, diabetes management and smoking cessation (NICE, 2014). ${ }^{1}$

Motivational interviewing (MI) can be defined as a 'collaborative communication style for strengthening a person's own motivation and commitment to change' (Miller \& Rollnick, 2013, p.12). ${ }^{3}$ This 'style' of communication can be described as having four key aspects: partnership, acceptance, compassion and evocation of change, all of which are underpinned by a patient-centred relationship between patient and practitioner (Rogers, 1961). ${ }^{4}$ The MI practitioner works with a patient to evoke change that is already present, awakening a motivation that comes from the patient and not the practitioner.

Two separate reviews by Gao, et $a l^{5}$ and Cascaes et $a \mathrm{l}^{6}{ }^{6}$ examined a total of 26 randomised controlled trials in order to assess the effectiveness of motivational interviewing on oral health-related clinical and behavioural outcomes.

The effectiveness of motivational interviewing was measured in comparison to giving conventional education (CE). In terms of the search strategies used, Cascaes et al. appear to have conducted a wider search although retrieved fewer papers, which raises some questions. Across the two reviews there was an overlap of seven studies.

The design and delivery of the motivational interviewing intervention differed across studies, ranging from one to seven MI sessions, lasting between five and 90 minutes, being delivered by different healthcare professionals (with and without previous MI experience), administered on adults, adolescents and parents with young children. Follow-up times, after the intervention was delivered, ranged from one month to two years. In terms of outcomes, a variety of target behaviours and oral health outcomes were assessed using a number of clinical and self-report measures.

Both reviews found that the studies provided inconclusive evidence for effectiveness across most clinical and behavioural outcomes. Furthermore, results showing effectiveness were often contradictory with positive results for shorter follow-up times found in studies regarding periodontal health, ${ }^{5}$ or for studies rated as having lower quality. ${ }^{6}$

Reporting on studies investigating clinical and behavioural outcome measures, there was some evidence of positive MI effect for reducing dental caries in children through changing parental behaviour. ${ }^{7}$ This study appeared in both reviews and was rated as having good quality. Also reported as a good quality study in both reviews,
Godard $^{8}$ found positive effect of MI on reducing plaque and increasing patient satisfaction in adult patients with moderate to severe periodontitis, through increasing brushing.

Almomani ${ }^{9}$ reported a positive MI effect on tooth-brushing and reduced plaque in adults with severe mental illness. To summarise, these three studies showed consistent positive effects of MI on clinical and behavioural outcomes and were the only three to be rated as good quality by both review papers. A limitation is that there is little clarity as to how the interventions worked as this was unreported by the systematic review authors.

As with many systematic reviews, there is considerable heterogeneity across the included studies in terms of populations, measures and outcomes. Consequently this restricted any quantitative assessment. Both reviews highlight how the quality of evidence is varied with differing outcome measures being used, some of which have faced critique, for example, use of caries increment as an outcome measure has been highlighted by Slade and Caplan ${ }^{10}$ as perhaps an over simplistic way of demonstrating outcomes. Furthermore the reviews draw attention to the lack of uniformity in clinical definitions and little fidelity assessment of intervention content.

On comparing the quality ratings of these studies, two out of the seven had been given ratings that differed by more than two points (when the rating scales were adjusted), this shows some inconsistency in quality assessment across the reviews.

The conclusions drawn from both are inconclusive due to mixed results and evidence differing in quality. However, they provide future researchers with an opportunity to conduct more rigorous intervention studies and build upon limited existing evidence for using MI in a dental setting. Future randomised control trials should adhere to guidelines from the Consolidated Standards of Reporting Trials (CONSORT) statement (www.consort-statement.org/)

Fundamentally there is a need to recognise behaviour change as a science and understand the specific mechanisms that change that behaviour. Although motivational interviewing has been found successful in changing certain behaviours in certain settings, it is essentially a style of communication that is underpinned by psychological behaviour change theory.

Michie and Johnston ${ }^{11}$ argue that if we are to advance our scientific understanding of behaviour change, we must make conceptual and methodological advances in the area. Most relevant to dentistry and the application of MI is developing our understanding of the principles of behaviour change.

Standardised 'active ingredients' must be used if we are to adequately design, evaluate, report and replicate interventions. Active ingredients must be described in terms of the precise behaviour to be changed, behaviour change techniques employed (for example, goal setting, biofeedback, framing/reframing, identification of self as a role model), competencies required to deliver them, mode of delivery and level of intervention.

A behaviour change technique (BCT) can be described as an irreducible component of a behaviour change intervention; these are really the key components of any intervention. ${ }^{11}$

Over 100 techniques have been identified and categorised into one of three groups depending on how they change behaviour. Some techniques motivate people to change behaviour, others enable people to act and the third group prompt. Further explanation can be found in the Health Behaviour Change Competency Framework. ${ }^{12}$ 
There is evidence to support certain behaviour change techniques successfully targeting specific behaviour. For example 'self-monitoring' is effective for supporting a healthy diet Michie, et al. ${ }^{13}$ With reference to the two reviews in this commentary, they have included a wide variety of target behaviours, each complex, with a multitude of factors influencing them. In the future MI interventions should be developed and understood in terms of behaviour change theory relating to specific behaviours. The MI intervention must be dissected into its irreducible component parts (behaviour change techniques) so that there is opportunity to understand the mechanisms of change if a positive effect is found.

Although most of the studies included in the reviews have used clinical outcome measures (for example, dental caries or plaque reduction), this end point is a consequence of behaviour, not the behaviour itself. It is usually impossible to say that an intervention was the causal influence of a desired clinical outcome when we take into account external influences.

Both reviews suggest that we should therefore be cautious in choosing outcomes to measure and try to include measures of behaviour and psychological factors. By measuring these additional variables, the mechanisms of behaviour change may become clearer, increasing our understanding of how the intervention worked in order to replicate and improve it.

In conclusion, Gao et al. 5 and Cascaes et al. 6 have successfully gathered studies assessing the effects of MI on oral health outcomes. In doing so, they have demonstrated the need for further intervention studies targeting specific behaviours. Due to the complexity of behaviour and multitude of influencing factors, it is impossible to draw conclusions on effectiveness without a more substantial, comparable and high quality evidence base. Future systematic reviews in this area may benefit from a narrower focus.

Ellen Jardine and Valerie White

Department of Public Health, NHS Dumfries \& Galloway,

Crichton Hall, Dumfries, Scotland

1. NICE (2014). Individual Approaches to Behaviour Change Retrieved on 26th May 2014. From: http://guidance.nice.org.uk/PH49

2. Healthcare Improvement Scotland (2014). SIGN 138 - Dental Interventions to prevent caries in children Retrieved on 26th May 2014. From: http://www.sign. ac.uk/pdf/SIGN138.pdf

3. Miller WR, Rollnick S. Motivational interviewing: Helping people change 3rd ed. p12. Guilford Press 2012

4. Rogers C. On becoming a person: A therapist's view of psychotherapy Houghton Mifflin Harcourt, 2012.

5. Gao X, Lo EC, Kot SC, Wai Chan KC. Motivational interviewing in improving ora health: a systematic review of randomized controlled trials. / Periodontol 2014; 85: 426-437.

6. Cascaes AM, Bielemann RM, Clark VL, Barros AJ. Effectiveness of motivational interviewing at improving oral health: a systematic review. Rev Saude Publica 2014; 48: 142-153.

7. Harrison R, Benton T, Everson-Stewart S, Weinstein P. Effect of motivational interviewing on rates of early childhood caries: a randomized trial. Pediatr Dent 2007; 29: 16-22

8. Godard A, Dufour T, Jeanne S. Application of self-regulation theory and motivational interview for improving oral hygiene: a randomized controlled trial. I Clin Periodontol 2011: 38: 1099-1105.

9. Almomani F, Williams K, Catley D, Brown C. Effects of an oral health promotion program in people with mental illness. J Dent Res 2009; 88: 648-652.

10. Slade GD, Caplan DJ. Methodological issues on longitudinal epidemiological studies of dental caries. Community Dent Oral Epidemiol 1999; 27: 236-248.

11. Michie S, Johnston M. Theories and techniques of behaviour change: Developing a cumulative science of behaviour change. Health Psychol Rev 2012; 6: 1-6.

12. NHS Health Scotland (2010). Health Behaviour Change Competency Framework Retrieved on 26th May 2014. From: http://www.healthscotland.com/ documents/4877.aspx

13. Michie S, Abraham C, Whittington C, McAteer J, Gupta S. Effective techniques in healthy eating and physical activity interventions: a meta-regression. Health Psychol 2009; 28: 690-701.

Evidence-Based Dentistry (2014), 15, 35-37. doi: 10.1038/sj.ebd.6401018 